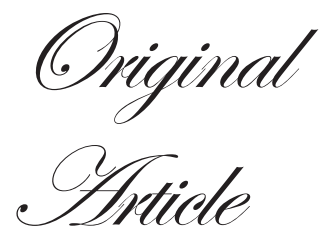

\title{
Learning curve, diagnostic yield and safety of single balloon enteroscopy
}

\author{
Amit Kumar Dutta, Kattiparambil Gangadharan Sajith, Anjilivelil J \\ Joseph, Ebby George Simon, Ashok Chacko
}

\section{ABSTRACT}

Department of Gastrointestinal Sciences,

Christian Medical College and Hospital,

Vellore - 632004 ,

Tamil Nadu, India.

Correspondence:

Dr. Ashok Chacko

Email: gastro@cmcvellore.ac.in
Background: Single balloon enteroscopy (SBE) is a recently developed diagnostic modality to assess small bowel mucosa. The data on learning curve of SBE is scanty. We aimed to assess the learning curve, diagnostic yield and safety of SBE

Methods: All patients who underwent SBE at our centre from December 2007 to December 2010 were included retrospectively. The clinical details, enteroscopy findings and procedure related details were obtained for each patient from a prospectively maintained database. The extent of small bowel visualised with increasing number of procedures by a single endoscopist (Endoscopist A) who performed most of the procedures was used to estimate the learning curve using locally weighted regression curve. The diagnostic yield and complications rates of SBE were also estimated. The study was approved by the institute review board and ethics committee.

Results: Ninety SBEs were performed in 84 patients (age: $42+15$ years, $27.4 \%$ females). 57 procedures were performed ( 32 antegrade and 25 retrograde) by endoscopist A. There was gradual improvement in the extent of small bowel visualised during the first 15 procedures via antegrade route followed by flattening of curve. The retrograde route showed no definite trend towards improvement during the procedures performed. The overall diagnostic yield of SBE was $32.1 \%$. There was no complication except for mild self-limiting abdominal pain in one patient.

Conclusions: SBE via antegrade route has a higher success rate and better learning curve than the retrograde route. SBE is a safe procedure and helps in establishing a diagnosis in one-third of the patients examined.

KEYWORDS: Learning curve, safety, single balloon enteroscopy, antegrade route

\section{Introduction}

Visualisation of the small intestinal mucosal surface remained a challenge until the introduction of the capsule endoscope in $2001 .^{1}$ This technique soon gained popularity all over the world. ${ }^{2}$ However, the inability to perform biopsies or therapeutic manoeuvres was a significant limitation of capsule endoscopy. To overcome this, enteroscopy systems have been developed that can traverse the small intestine and at the same time provide an opportunity to take tissue samples or perform therapy. ${ }^{3}$ The first such system was a double balloon enteroscope which was followed by the single balloon enteroscope. ${ }^{4,5}$ Spiral enteroscopy has been the latest addition. ${ }^{6}$ These systems differ in the technical and procedural details but all of them strive to visualise as much of the small bowel as possible. ${ }^{7-10}$ While sufficient data exists on the safety and yield of double balloon enteroscopy, data on efficacy of single balloon enteroscopy (SBE) is still emerging. ${ }^{11,12}$ The data on learning curve of SBE 
via the antegrade and retrograde route is scanty. ${ }^{13}$ The aim of the present study therefore, was to assess the safety and diagnostic yield of single balloon enteroscopy at our center. Since most of the SBE procedures at our center were performed by the same endoscopist, we also assessed the learning curve of the procedure via the antegrade and retrograde routes with respect to the extent of small intestine visualised.

\section{Methods}

Single balloon enteroscopy facility has been available at our center since December 2007. This study retrospectively included all the patients who underwent this procedure upto December 2010. An Olympus single balloon enteroscopy system (SIF Q180) was used for all the procedures. The system includes a flexible video-enteroscope ( $2 \mathrm{~m}$ length), an overtube $(140 \mathrm{~cm}$ length) with a balloon at its tip, a balloon control pump and a high definition video monitor. The procedure was performed via oral (antegrade) and/or anal (retrograde) route by a single endoscopist with two assistants (one controlling the overtube, balloon pump and keeping the part of enteroscope outside the oral cavity in a straight position and the other holding the enteroscope and mouth gag in position next to the oral cavity). The enteroscope was advanced into the small bowel, followed by advancement of the overtube till it reached near the bending unit of the enteroscope. The balloon on the overtube was then inflated, the endoscope tip angled and the overtube and the enteroscope collectively withdrawn. ${ }^{14}$ Repetition of this 'push/ pull' technique shortened the proximal small bowel and allowed progress of the endoscope distally. The procedure was performed till no further advancement was possible or required. For the procedure via the retrograde route, bowel preparation was done by administering $137.15 \mathrm{~g}$ of polyethylene glycol in 2 litres of water orally on the previous evening and on the morning of the procedure. ${ }^{13}$ No preparation was required for antegrade route enteroscopy except for overnight fasting prior to the procedure. The procedure via the retrograde route was generally performed using sedation with midazolam while the oral route required propofol. Fluoroscopic guidance was used for all the patients during the procedure. The procedure time varied from half an hour to one and half hour although the exact time was not recorded.

The enteroscopy was performed by three endoscopists. In the first year, a single endoscopist (Endoscopist A, who did not have any prior formal training or hands on experience of the procedure) performed all the procedures. The technique was learnt by reading literature, attending workshops and watching videos. The engineers from the endoscope company provided technical support during the first two procedures. Two more endoscopists started performing the procedure after the first year. Written informed consent for the procedure was obtained from all the patients. The findings were recorded on a standard reporting format using a software designed for endoscopy reporting (Image Plus, Avantec). The distance traversed was calculated by adding the length advanced in each push/pull cycle and subtracting the slippage distance. ${ }^{15}$ The median distance traversed was measured from the pyloric ring for the antegrade route and from the IC valve for the retrograde route. The procedure was considered successful if the endoscope could be negotiated beyond the duodenojejunal flexure via the antegrade route or beyond $20 \mathrm{~cm}$ of the terminal ileum via the retrograde route. ${ }^{16}$ The route of the procedure was decided by the referring physician based on the clinical data and/or imaging reports showing the location of the lesion.

The epidemiological, clinical, laboratory and other investigation details, enteroscopy findings and procedure related complications were recorded systematically for each patient by a single investigator. These records were reviewed by a second investigator to ensure data accuracy. Crohn's disease was diagnosed based on a combination of clinical, endoscopic, radiological and histological features. ${ }^{17}$ Tuberculosis was diagnosed if biopsy of the lesion showed acid fast bacilli or necrotising granulomas with clinical response after anti-tubercular therapy. ${ }^{18}$ Presence of villous atrophy and crypt hyperplasia and response to gluten free diet was suggestive of celiac disease. ${ }^{19}$ Vascular lesions were confirmed by endoscopic appearance and histology. ${ }^{20}$ Other lesions were diagnosed based on mucosal findings, clinical details and biopsy reports. ${ }^{21}$ The extent of the small bowel visualised, diagnostic yield, and procedure failure and complications rates were estimated. The study was approved by the institute review board and ethics committee.

\section{Statistical analysis}

Categorical data are presented as proportions. Continuous data with normal distribution are presented as mean with standard deviations, while the non-normally distributed data are presented as median with range. Comparison of the extent of small bowel visualised during procedure via the anal and oral 
routes is done using Mann Whitney's U test. Scatter plot with locally weighted regression (LOESS fit) with a smoothing parameter of 0.5 was used to depict the learning curve of antegrade and retrograde techniques. ${ }^{22}$ Data analysis was done using SPSS for Windows version 15.0.

\section{Results}

Single balloon enteroscopy was performed in 84 patients during the study period. Their mean age was $42+15$ years and 23 $(27.4 \%)$ of them were females. No patient had surgically altered anatomy like gastrojejunostomy or ileocecal resection. Antegrade route of examination was used in 42 patients, retrograde route in 36 patients and both routes in 6 patients. Thus, a total of 48 antegrade and 42 retrograde procedures were performed. The procedure was unsuccessful in 5 patients (all via retrograde route). In eight retrograde and one antegrade procedures, endoscope advancement was limited by luminal narrowing. In the remaining 76 procedures, the median length of small bowel visualised during antegrade examination was $100 \mathrm{~cm}(\mathrm{n}=47$, range $15-200 \mathrm{~cm})$ and the median ileal length visualised during retrograde examination was $75 \mathrm{~cm}(\mathrm{n}=29$, range 25-200 cm). The difference in the extent of small bowel visualised using the two routes was statistically significant $(\mathrm{p}=0.02)$. No patient had a complete small bowel examination. There was no complication associated with the procedure except for mild self-limiting abdominal pain in one patient.

Table 1 shows the indications for single balloon enteroscopy and the findings during the procedure. The commonest indication was for evaluating suspected Crohn's disease $(41.7 \%)$ followed by obscure gastrointestinal bleed $(31 \%)$. The five patients in other categories included two with sub-acute intestinal obstruction, one with a disseminated adenocarcinoma with small bowel narrowing planned for luminal metallic stenting, one patient with jejunojejunal intussussception on imaging and one patient who had cutaneous lymphoma with suspected small intestinal lesions. The common endoscopic findings were small bowel strictures, mucosal nodularity and ulcerations. Apart from targeted biopsy of lesions, random biopsies from normal appearing intestinal mucosa were obtained from all patients with suspected Crohn's disease, abdominal pain and malabsorption. The overall diagnostic yield of the procedure was $32.1 \%$ and Crohn's disease was the most frequent diagnosis (17 patients). The yield was highest in patients with suspected Crohn's disease (54.3\% of 35 patients) while it was lower in remaining groups, including patients with obscure gastrointestinal bleeding. The vascular lesions seen in the two patients with angiodysplasia were not typical in appearance and hence biopsy was required in them. None of the patients in the 'others' group had an abnormality detected during SBE. The two patients with subacute intestinal obstruction underwent laparotomy and were found to have small bowel strictures.

For estimating the learning curve of SBE, procedures performed by Endoscopist A were included. The number of procedures done by the other two endoscopists were too small to be included for analysis. Endoscopist A performed 57 procedures in all, which included 32 antegrade and 25 retrograde

Table 1: Indications and findings on single balloon enteroscopy

\begin{tabular}{|c|c|}
\hline $\begin{array}{l}\text { Indications } \\
(n=84)\end{array}$ & Enteroscopy findings and diagnosis \\
\hline Suspected CD-35 & $\begin{array}{l}\text { Stricture with mucosal ulcerations - } 9 \text { (CD-7; Ischemic stricture-1; Diffuse large B cell Lymphoma-1) } \\
\text { Mucosal ulcerations - } 5 \text { (CD-3; Tuberculosis -2)Mucosal nodularity with ulcerations - } 3 \text { (CD3) } \\
\text { Mucosal edema and erythema - } 2 \text { (CD-2) } \\
\text { Normal mucosa and histology -16 }\end{array}$ \\
\hline Obscure GI Bleed - 26 & $\begin{array}{l}\text { Vascular lesion of mucosa }-2 \text { (angiodysplasia } 2) \\
\text { Stricture with ulcerations }-1 \text { (CD) } \\
\text { Hookworm }-1 \\
\text { Normal mucosa - } 22\end{array}$ \\
\hline Abdominal Pain - 10 & $\begin{array}{l}\text { Mucosal nodularity with ulcerations }-1 \text { (ischemic stricture) } \\
\text { Polypoid congested mass lesion - } 1 \text { (inflammatory fibroid polyp) } \\
\text { Normal mucosa and histology }-8\end{array}$ \\
\hline Suspected Malabsorption - 8 & $\begin{array}{l}\text { Mucosal ulcerations }-1(\mathrm{CD}) \\
\text { Normal mucosa with histology suggestive of celiac disease - } 1 \\
\text { Normal mucosa and histology - } 6\end{array}$ \\
\hline Others -5 & Normal mucosa -5 \\
\hline
\end{tabular}

CD-Crohn's disease 

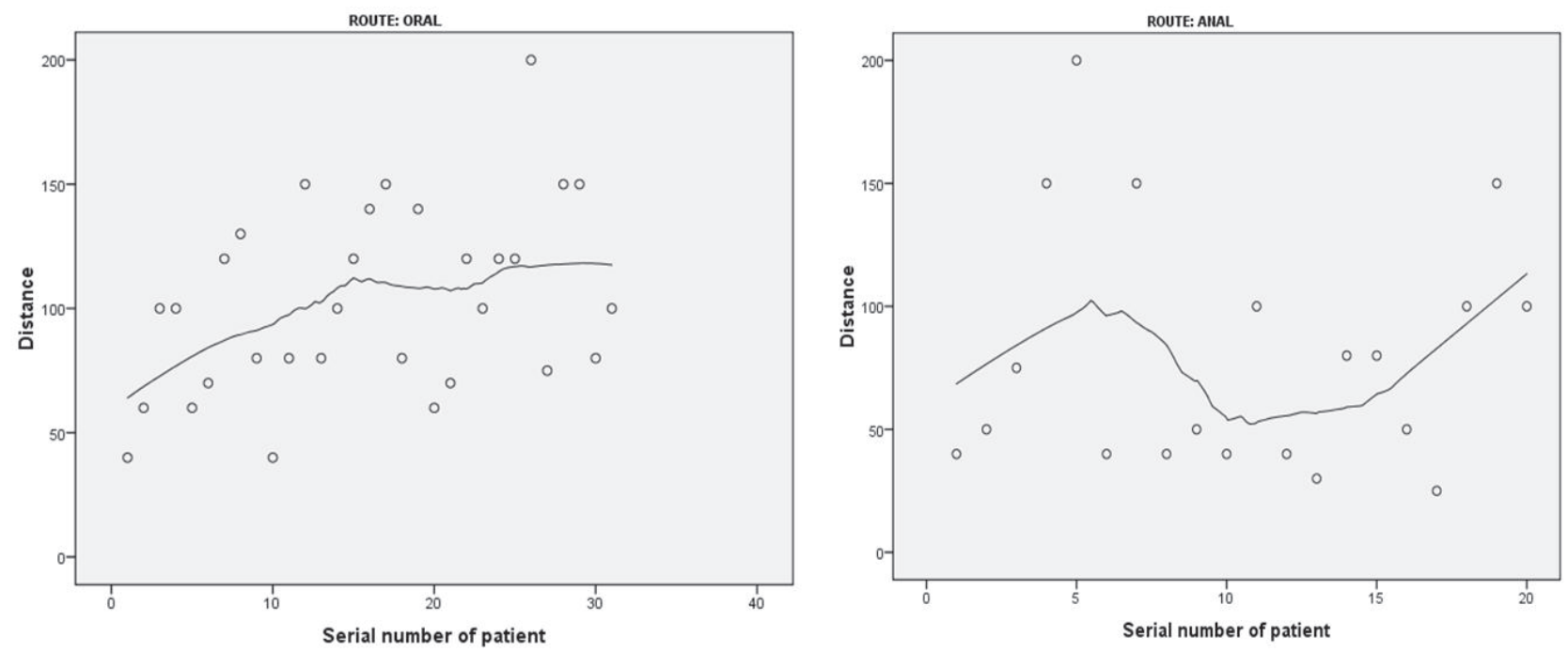

Figure 1: Scatter plots with locally weighted regression curve showing the extent of small bowel traversed (distance) during SBE by endoscopist A using oral and anal routes with increasing number of patients

procedures. The retrograde examination was unsuccessful in three patients. The antegrade examination in one patient and retrograde examination in two patients was cut short due to luminal narrowing. Data from the remaining 51 patients were used to estimate the learning curve (31 antegrade, 20 retrograde) as shown in Figure 1. There was gradual improvement during the first 15 procedures via the antegrade route followed by flattening of the curve. The retrograde route showed no definite trend towards improvement during the 20 procedures performed.

\section{Discussion}

This study reports performance characteristics, diagnostic yield and safety of SBE at our center over the past 3 years. Technical success and extent of the bowel examined was better with the antegrade route. The median length of jejunum seen during the first 15 procedures by Endoscopist A was $80 \mathrm{~cm}$ (range 40$150 \mathrm{~cm}$ ) and in the subsequent 16 procedures it increased to $120 \mathrm{~cm}$ (range 60-200 cm). There was no obvious trend of improvement with increasing experience for the retrograde route. A recent report on $173 \mathrm{SBE}$ (83\% antegrade, 17\% retrograde) from the USA showed the median depth during oral route to be $132 \mathrm{~cm}$ (range $20-400 \mathrm{~cm}$ ) and rectal route to be $73 \mathrm{~cm}$ (range 10-160 cm). ${ }^{13}$ This is comparable to our result for the oral route after the first 15 procedures and rectal route in general. This suggests that SBE via the oral route has a relatively faster learning curve while retrograde examination seems to be technically more demanding and difficult to improve upon. For DBE, the performance of retrograde procedure has been shown to improve after 20 procedures. ${ }^{16}$ However, the average length of small bowel seen during rectal route examination by DBE is also significantly less than that via the oral route examination. ${ }^{16,23}$ Hence, this area requires further research and development to improve performance.

The diagnostic yield of SBE in our series was only $32.1 \%$. This is less compared to about $45-60 \%$ yield reported from other series. ${ }^{7,8,13,24}$ One reason may be the poor yield in patients with obscure GI bleeds (16\%) compared to other series. The low yield is due to the limited length of small bowel seen, as seven out of eight patients with obscure bleed and normal SBE were found to have small bowel lesions (Crohn's disease in five and angiodysplasia in two) on subsequent capsule endoscopy. The group with abdominal pain and suspected malabsorption also had a poor yield. Our center has no experience in DBE and hence we do not have any local data to compare the yields of SBE and DBE, but studies have clearly shown DBE to have better yield than SBE due to greater length of bowel examined and higher rate of complete small bowel examination. ${ }^{7}$ A previous report from our center on capsule endoscopy in obscure gastrointestinal bleed showed the diagnostic yield to be $75.2 \%$ in the 133 patients evaluated. ${ }^{25}$ This highlights the fact that balloon enteroscopy and capsule endoscopy have their specific benefits, which are complementary. ${ }^{26,27}$ Capsule endoscopy provides complete small bowel examination in majority of the cases, while balloon enteroscopy provides the opportunity to sample tissue and perform therapy. ${ }^{28,29}$

Our study confirms the safety of SBE in patients with suspected small bowel disorders. Only one patient reported 
abdominal pain after retrograde SBE which resolved within 4 hours. We performed 58 mucosal biopsies during SBE and no patient suffered any bleed or perforation. There were no adverse events related to sedation or anaesthesia. One report showed hyperamylasemia in $16 \%$ of the 105 patients after undergoing SBE, but none had clinical symptoms. ${ }^{12}$ Rarely, perforation has been reported during the procedure. ${ }^{8,12}$ These findings reassure us of the minimal adverse event potential of SBE. Our study spanned a period of over 3 years and during this period we could generate the learning curve of one endoscopist. It would take several years at a single center or require a multicenter study to generate learning curves of multiple endoscopists. Another limitation of our study is the relatively smaller number of patients in the retrograde route group where examination was not hindered due to technical failure or luminal narrowing. Adequate data on learning curve of retrograde route SBE may be difficult to obtain as retrograde examination is performed less often than oral examination. The technique of distance measurement has a subjective component, although the error rate in measurement has been shown to be less than $10 \%$ by the method described in this study. ${ }^{15}$ Although we used fluoroscopy in all our patients, the advantage of fluoroscopy during the procedure is unclear and a recent study on double balloon enteroscopy showed no added benefit of fluoroscopy in terms of depth of insertion, procedure time or diagnostic yield. ${ }^{30}$

In conclusion $\mathrm{SBE}$ via antegrade route has a higher success rate and better learning curve than retrograde route. The procedure is safe and helps in establishing a diagnosis in onethird of the patients examined. As SBE is performed in a limited number of centres, more data on learning curve, technical difficulties, limitations and diagnostic yield will help in better understanding of its role in evaluating small bowel disorders.

\section{References}

1. Appleyard M, Glukhovsky A, Swain P. Wireless-capsule diagnostic endoscopy for recurrent small-bowel bleeding. $N$ Engl JMed. 2001;344:232-3.

2. Marmo R, Rotondano G, Piscopo R, Bianco MA, Cipolletta L. Meta-analysis: capsule enteroscopy vs. conventional modalities in diagnosis of small bowel diseases. Aliment Pharmacol Ther 2005;22:595-604.

3. Semrad CE. Small bowel enteroscopy: territory conquered, future horizons. Curr Opin Gastroenterol. 2009;25:110-5.

4. Yamamoto H, Kita H, Sunada K, Hayashi Y, Sato H, Yano T, et al. Clinical outcomes of double-balloon endoscopy for the diagnosis and treatment of small-intestinal diseases. Clin Gastroenterol Hepatol. 2004;2:1010-6.
5. Kawamura T, Yasuda K, Tanaka K, Uno K, Ueda M, Sanada K, et al. Clinical evaluation of a newly developed single-balloon enteroscope. Gastrointest Endosc. 2008;68:1112-6.

6. Akerman PA, Agrawal D, Chen W, Cantero D, Avila J, Pangtay J. Spiral enteroscopy: a novel method of enteroscopy by using the Endo-Ease Discovery SB overtube and a pediatric colonoscope. Gastrointest Endosc. 2009;69:327-32.

7. May A, Färber M, Aschmoneit I, Pohl J, Manner H, Lotterer E, et al. Prospective multicenter trial comparing push-and-pull enteroscopy with the single- and double-balloon techniques in patients with small-bowel disorders. Am J Gastroenterol. 2010;105:575-81.

8. Khashab MA, Lennon AM, Dunbar KB, Singh VK, Chandrasekhara V, Giday S, et al. A comparative evaluation of single-balloon enteroscopy and spiral enteroscopy for patients with mid-gut disorders. Gastrointest Endosc. 2010;72:766-72.

9. Morgan D, Upchurch B, Draganov P, Binmoeller KF, Haluszka O, Jonnalagadda $S$, et al. Spiral enteroscopy: prospective U.S. multicenter study in patients with small-bowel disorders. Gastrointest Endosc. 2010;72:992-8.

10. Frieling T, Heise J, Sassenrath W, Hulsdonk A, Kreysel C. Prospective comparison between double-balloon enteroscopy and spiral enteroscopy. Endoscopy. 2010;42:885-8.

11. Maaser C, Schmedt A, Bokemeyer M, Kannengiesser K, Ullerich H, Lügering A, Domagk D, et al. Long-term efficacy and safety of double balloon enteroscopy-prospective and retrospective data from a single center study. Scand J Gastroenterol. 2010;45:992-9.

12. Aktas H, de Ridder L, Haringsma J, Kuipers EJ, Mensink PB. Complications of single-balloon enteroscopy: a prospective evaluation of 166 procedures. Endoscopy. 2010;42:365-8.

13. Upchurch BR, Sanaka MR, Lopez AR, Vargo JJ. The clinical utility of single-balloon enteroscopy: a single-center experience of 172 procedures. Gastrointest Endosc. 2010;71:1218-23.

14. Upchurch BR, Vargo JJ. Single-balloon enteroscopy. Gastrointest Endosc Clin N Am. 2009;19:335-47.

15. May A, Nachbar L, Schneider M, Neumann M, Ell C. Push-andpull enteroscopy using the double-balloon technique: method of assessing depth of insertion and training of the enteroscopy technique using the Erlangen Endo-Trainer. Endoscopy. 2005;37:66-70.

16. Mehdizadeh S, Ross A, Gerson L, Leighton J, Chen A, Schembre $\mathrm{D}$, et al. What is the learning curve associated with double-balloon enteroscopy? Technical details and early experience in 6 U.S. tertiary care centers. Gastrointest Endosc. 2006;64:740-50.

17. Ouyang Q, Tandon R, Goh KL, Pan GZ, Fock KM, Fiocchi C, et al. Management consensus of inflammatory bowel disease for the Asia-Pacific region. $J$ Gastroenterol Hepatol. 2006;21:1772-82.

18. Sharma MP, Bhatia V. Abdominal tuberculosis. Indian J Med Res. 2004;120:305-15.

19. Catassi C, Fasano A. Celiac disease diagnosis: simple rules are better than complicated algorithms. Am J Med. 2010;123:691-3.

20. Dalle I, Geboes K. Vascular lesions of the gastrointestinal tract. Acta Gastroenterol Belg. 2002;65:213-9.

21. Haraguchi M, Matsushima S, Fujie Y, Sugimachi K. Ischemic stricture of the jejunum-report of a case. Jpn J Surg. 1990;20:715-9. 
22. Cleveland WS, Devlin SJ. Locally-weighted regression: an approach to regression analysis by local fitting. J Am Statistical Assoc. 1988;83:596-610.

23. Gross SA, Stark ME. Initial experience with double-balloon enteroscopy at a U.S. center. Gastrointest Endosc. 2008;67:890-7.

24. Frantz DJ, Dellon ES, Grimm IS, Morgan DR. Single-balloon enteroscopy: results from an initial experience at a U.S. tertiarycare center. Gastrointest Endosc. 2010;72:422-6.

25. Dutta AK, Chacko A, Simon EG, et al. Capsule endoscopy of small bowel -A large single center experience from India. J Dig Endoscopy. 2010;1:3-7.

26. Kamalaporn P, Cho S, Basset N, Cirocco M, May G, Kortan P, et al. Double-balloon enteroscopy following capsule endoscopy in the management of obscure gastrointestinal bleeding: outcome of a combined approach. Can J Gastroenterol. 2008;22:491-5.
27. Pasha SF, Leighton JA, Das A, Harrison ME, Decker GA, Fleischer DE, et al. Double-balloon enteroscopy and capsule endoscopy have comparable diagnostic yield in small-bowel disease: a meta-analysis. Clin Gastroenterol Hepatol. 2008;6:671-6.

28. Heinzow HS, Meister T, Wessling J, Domschke W, Ullerich H. Ileal gallstone obstruction: Single-balloon enteroscopic removal. World J Gastrointest Endosc. 2010;2:321-4.

29. Ohmiya N, Nakamura M, Takenaka H, Morishima K, Yamamura $\mathrm{T}$, Ishihara M, et al. Management of small-bowel polyps in PeutzJeghers syndrome by using enteroclysis, double-balloon enteroscopy, and videocapsule endoscopy. Gastrointest Endosc. 2010;72:1209-16.

30. Manner H, May A, Pohl J, Färber M, Ell C. Impact of fluoroscopy on oral double-balloon enteroscopy: results of a randomized trial in 156 patients. Endoscopy. 2010;42:820-6. 